\title{
Use of hospital palliative care according to the place of death and disease one year before death in 2013: a French national observational study
}

\author{
Claire Poulalhon ${ }^{1}$, Laureen Rotelli-Bihet ${ }^{2}$, Sébastien Moine ${ }^{3}$, Anne Fagot-Campagna', Régis Aubry ${ }^{4}$
} and Philippe Tuppin ${ }^{1 *}$

\begin{abstract}
Background: Only limited data are available concerning the diseases managed before death and hospital palliative care (HPC) use according to place of death in France. We therefore conducted an observational study based on administrative health data in a large population to identify the diseases treated one year before death in 2013, the place of stay with or without hospital palliative care, and the place of death.

Methods: French health insurance general scheme beneficiaries were identified in the National Health data Information System (Snds) with a selection of information. Diseases were identified by algorithms from reimbursement data recorded in the Snds database.

Results: 347,253 people were included in this study (61\% of all people who died in France). Place of death was short stay hospital for 51\%, Rehab (7\%), hospital at home (3\%), skilled nursing home (13\%) and other (26\%). Chronic diseases managed in 2013 before death were cardiovascular/neurovascular diseases (56\%), cancers (42\%), and neurological and degenerative diseases (25\%). During the year before death, $84 \%$ of people were hospitalized at least once, and $29 \%$ had received HPC. HPC was used by $52 \%$ of cancer patients (lung cancer: 62\%; prostate cancer: $41 \%)$. In the absence of cancer, the use of HPC varied according to the disease: acute stroke: $24 \%$, heart failure:

17\%, dementia: $17 \%$, multiple sclerosis: $23 \%$.
\end{abstract}

Conclusions: Health administrative data can refine the knowledge of the care pathway prior to death and the HPC utilisation and can be useful to evaluate heath policies and improve monitoring and assessment of HPC use.

Keywords: Palliative care, Hospital, Death, Health status, Administrative health data, Place of death, Cancer, End-oflife care

\section{Background}

By improving survival, technical and scientific progress in the field of medicine has resulted in a growing burden of chronic diseases and has modified the temporality of the end of life, which may involve the use of palliative care earlier in the course of the disease [1]. In France, one in four people were over the age of 60 years in 2013 for a population of 65.6 million inhabitants, and people

\footnotetext{
* Correspondence: philippe.tuppin@cnamts.fr

${ }^{1}$ National sickness insurance fund, 26-50, avenue du Professeur André Lemierre, 75986 Paris cedex 20, France

Full list of author information is available at the end of the article
}

over the age of 60 will represent almost one-third of the population in 2060 [2]. This ageing population will lead to an increased number of people with chronic fatal diseases requiring palliative care [3]. Three types of end-oflife pathways have been distinguished: rapid decline, gradual decline with episodes of decompensation, and slow and progressive decline [4]. End of life care is therefore not confined to the last instants of life, but corresponds to a longer period with a high level of health care consumption designed to relieve psychological distress, the patient's symptoms and provide support to caregivers. 
In France, a new national plan for the development of end-of-life palliative care and supportive care was launched in 2015 [5]. The previous plan (2008-2012) revealed deficiencies concerning the possibility of maintaining people at home at the end of life with differences in terms of access according to age, place of residence and disease [6]. However, only limited data are available, for France and other countries, concerning the place of death, palliative care needs, palliative care use and end-of-life care pathways according to the patient's characteristics and diseases. These data are derived from studies based on samples or subgroups determined according to the place of management or, more often, causes of death. Hospital diagnoses are less frequently studied using national healthcare administrative databases [7-19]. People needing palliative care in France have been estimated to represent $44 \%$ or $69 \%$ of deaths on the basis of causes of death associated with a theoretical indication for palliative care [7-9].

The objective of this observational study using administrative health data for a large population was to identify the diseases treated one year before death in 2013, the place of stay with and without hospital palliative care (HPC) and the place of death according to the characteristics of this population.

\section{Methods}

\section{Population and settings}

This observational study concerned all French national health insurance general scheme beneficiaries $(77 \%$ of the French population) who died in 2013. The study was confined to this scheme because it systematically records the vital status of its beneficiaries. Individuals without at least one healthcare refund in 2012 and 2013, allowing identification of diseases, and children born in 2013, were excluded. The national health database (Snds) was used to study the various types of hospitals or institutions: short-stay hospitals with acute wards and palliative care facilities (specific wards, mobile teams providing palliative care advice and expertise to other healthcare professionals) and specific beds; rehabilitation (rehab) hospitals, to which people are usually admitted after an acute hospital stay and which are devoted to rehabilitation as well as palliative care depending on their rehabilitation specialization; and hospital at home $(\mathrm{HaH})$ care delivered by hospital teams. Information on skilled nursing home ( $\mathrm{SNH}$ ) stays is available, but not for all retirement homes [20]. Information is not available for mobile teams not specifically attached to $\mathrm{HaH}$ units or for ambulatory palliative care provided by general practitioner. Palliative care is provided by specialists in hospital and mainly by general practitioners in $\mathrm{SNH}$. Guidelines on specific pathways and best practices are published by the French National Authority for Health (Haute Autorité de santé, www.has-sante.fr) [21].

\section{Data sources}

Data concerning the beneficiaries are collected in the Snds database, which comprises comprehensive, anonymous, individual data concerning all prescriptions, examinations and procedures reimbursed [22]. The Snds database does not contain information on clinical results related to visits, prescriptions or examinations. Nevertheless, it includes information on the presence of certain long-term diseases (LTD) eligible for $100 \%$ reimbursement of healthcare. All these data are linked to data concerning hospital stays provided by the French hospital discharge database (PMSI), and residence in SNH. LTD and hospital diagnoses are coded according to the international classification of diseases, 10th edition (ICD-10). There is no data on causes of death.

\section{Data and frequency analysis}

HPC in short stay hospitals, Rehab and $\mathrm{HaH}$ was identified through palliative care diagnostic codes, specific palliative care beds or classification of the palliative care stay according to the various types of hospitalization. Use of HPC was calculated over the year preceding death including the date of death and at the date of death only. The totals indicated in the tables refer to people receiving HPC during the year before death or at the date of death during the last hospital stay. Information on place of death is available for deaths occurring during hospital stays (short stay hospitals, Rehab or $\mathrm{HaH}$ ) or in a SNH. Nevertheless, among the "other places" of death, it is not possible to distinguish death at home and death outside home: in a retirement home, in public places, etc. The Caisse Nationale d'Assurance Maladie (Cnam) general health scheme fund has developed a tool based on Snds data with algorithms designed to identify beneficiaries reimbursed for chronic diseases and common, serious or expensive diseases and treatments, in order to study these diseases in terms of numbers, prevalence rates, expenditure and annual growth [23]. Information concerning the patients' diseases in 2012 and in 2013 was derived from this tool (Additional file 1). Algorithms identify 56 non-exclusive groups of diseases, classified into 13 main categories, based on principal diagnoses, related or significant associated diagnoses in short-stay hospitals and psychiatric hospitals coded according to ICD-10; long-term disease diagnoses (LTD); dispensing of specific drugs; and specific procedures. Schematically, the term "acute" refers to hospitalization during the year with an appropriate ICD10 code and the chronic phase is defined by attribution of LTD status during the year and/or hospitalization with specific codes during the last 5 years. The acute episode always takes precedence to a chronic phase and these two groups are mutually exclusive for a given disease. Cancer is defined by short-stay hospitalizations over a 5 -year period (specific cancer diagnoses and chemotherapy and radiotherapy codes) and/or LTD status attributed over the previous 
2 years. In Tables 2 and 3, two groups were selected: patients with at less a diagnosis of a cancer and patients without diagnosis of cancer but with one or more other diseases. These definitions were submitted to sensitivity analyses concerning the numbers of subjects and the expenditure incurred, and a critical review was conducted by an independent partner, allowing improvement of these algorithms [24].

Characteristics of people died in 2013 were described including age, gender, residence in a $\mathrm{SNH}$, diseases identified by algorithms, and the presence of at least one admission the year before death in each type of hospital and/or on the day of death. Rates of subjects with HPC among all the subjects died in each type of hospital were also calculated according to subject characteristics and diseases. Figure 1 represents the place of stay of beneficiaries on a given day during the year preceding death.
All frequencies were calculated with SAS Enterprise Guide software (version 4.3; SAS Institute Inc., Cary, NC, USA).

\section{Results \\ Characteristics}

A total of 347,253 general scheme beneficiaries who died in 2013 were included (49.7\% men and 50.3\% of women) (Table 1). The mean age of death was 77 years (73 years for men, 81 years for women). Deaths before the age of 85 years predominantly concerned men, with a particularly marked sex difference between the ages of 15 and 35 years.

Globally, the diseases most commonly managed before death were cardiovascular/neurovascular diseases (56\%), especially heart failure (24\%), particularly in women and the oldest people, and coronary heart disease (20\%), which was more frequent in men. Deceased people had been managed for cancer in $42 \%$ of cases (close to $60 \%$

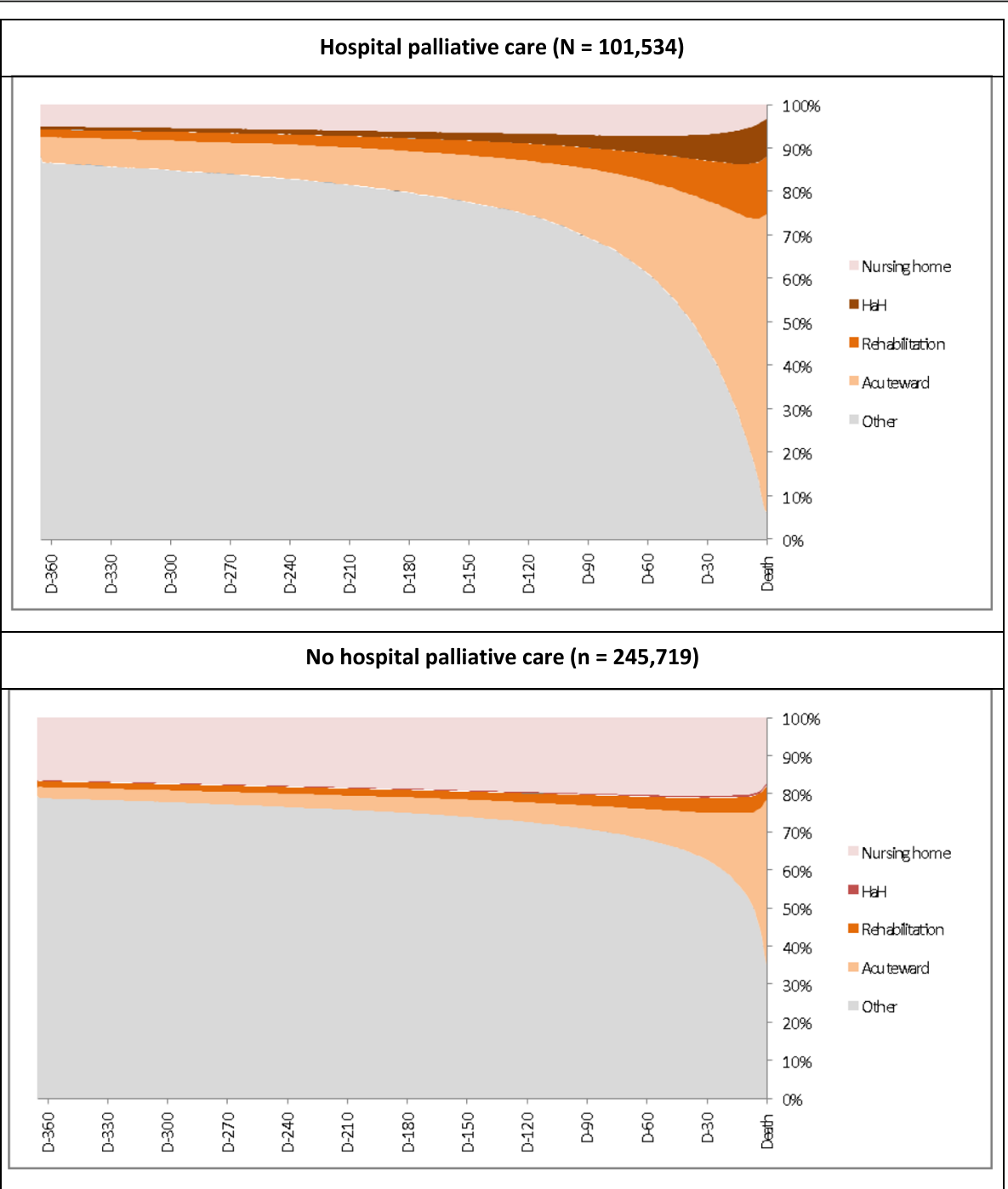

Fig. 1 Setting on a given day the year preceding death and hospital palliative care use 
Table 1 Diseases managed of general scheme beneficiaries who died in 2013, according to sex and age

\begin{tabular}{|c|c|c|c|c|c|c|c|c|c|c|c|c|}
\hline & \multirow[t]{2}{*}{ Total } & \multicolumn{2}{|l|}{ Sex } & \multicolumn{9}{|l|}{ Age } \\
\hline & & Men & Women & $<15$ & $15-34$ & $35-44$ & $45-54$ & $55-64$ & $65-74$ & $75-84$ & $85-94$ & $\geq 95$ \\
\hline N & 347,253 & 172,591 & 174,662 & 1066 & 4409 & 7030 & 18,860 & 39,656 & 50,638 & 89,933 & 114,652 & 21,009 \\
\hline \multirow[t]{2}{*}{$\%$} & 100.0 & 49.7 & 50.3 & 0.3 & 1.3 & 2.0 & 5.4 & 11.4 & 14.6 & 25.9 & 33.0 & 6.1 \\
\hline & $\%$ & $\%$ & $\%$ & $\%$ & $\%$ & $\%$ & $\%$ & $\%$ & $\%$ & $\%$ & $\%$ & $\%$ \\
\hline Women & 50.3 & - & - & 42.6 & 32.3 & 37.2 & 37.2 & 34.0 & 35.6 & 46.7 & 63.4 & 80.9 \\
\hline Age (mean years) & 77.0 & 73.2 & 80.7 & - & - & - & - & - & - & - & - & - \\
\hline Skilled nursing home resident & 21.1 & 12.8 & 29.3 & - & - & - & - & 1.8 & 5.1 & 14.0 & 30.4 & 42.5 \\
\hline At least one hospitalisation during the year & 83.5 & 85.4 & 81.6 & 81.1 & 59.1 & 70.6 & 80.2 & 85.5 & 88.5 & 87.6 & 82.8 & 66.5 \\
\hline Short stay hospitals & 82.8 & 84.9 & 80.7 & 80.9 & 58.8 & 70.1 & 79.7 & 85.1 & 88.1 & 86.9 & 81.9 & 65.3 \\
\hline Rehabilitation & 22.6 & 21.3 & 24.0 & 8.4 & 5.8 & 8.9 & 12.9 & 16.0 & 19.9 & 26.4 & 27.2 & 17.8 \\
\hline Hospital at home & 6.6 & 7.0 & 6.2 & 12.7 & 6.1 & 8.2 & 9.5 & 10.1 & 9.3 & 6.8 & 4.1 & 2.6 \\
\hline \multicolumn{13}{|l|}{ Diseases managed } \\
\hline Cardiovascular/neurovascular diseases & 56.5 & 58.4 & 54.6 & 16.5 & 11.4 & 16.3 & 24.6 & 37.9 & 50.8 & 63.2 & 68.8 & 62.4 \\
\hline Coronary heart disease & 20.5 & 24.6 & 16.4 & 0.5 & 1.2 & 3.6 & 7.8 & 13.9 & 20.4 & 24.3 & 24.0 & 20.3 \\
\hline Acute stroke & 4.9 & 4.2 & 5.7 & 1.3 & 1.6 & 2.9 & 2.9 & 3.1 & 4.0 & 5.9 & 6.0 & 3.8 \\
\hline Stroke sequelae & 9.5 & 9.6 & 9.4 & 5.1 & 2.7 & 2.8 & 4.0 & 5.9 & 8.4 & 10.8 & 11.7 & 10.4 \\
\hline Heart failure & 24.3 & 23.0 & 25.7 & 5.3 & 3.5 & 4.5 & 6.5 & 10.5 & 17.2 & 26.7 & 34.2 & 32.0 \\
\hline Peripheral artery disease & 10.7 & 13.8 & 7.6 & 0.5 & 0.5 & 1.1 & 4.1 & 9.7 & 12.5 & 12.6 & 11.2 & 9.0 \\
\hline Arrhythmia & 27.5 & 28.0 & 27.0 & 4.0 & 3.1 & 4.6 & 6.9 & 12.3 & 21.1 & 32.5 & 37.4 & 28.0 \\
\hline Valvular disease & 6.8 & 6.5 & 7.0 & 0.3 & 0.8 & 1.5 & 1.7 & 3.0 & 5.4 & 8.5 & 9.0 & 5.4 \\
\hline Pulmonary embolism & 1.1 & 1.0 & 1.2 & 0.2 & 0.5 & 0.9 & 1.1 & 1.4 & 1.5 & 1.2 & 1.0 & 0.5 \\
\hline Diabetes & 21.1 & 23.5 & 18.7 & 0.2 & 2.1 & 5.3 & 10.6 & 19.5 & 28.5 & 27.6 & 18.9 & 10.3 \\
\hline Cancers & 42.1 & 48.7 & 35.6 & 20.6 & 17.5 & 31.2 & 47.1 & 58.3 & 58.7 & 46.6 & 31.1 & 17.9 \\
\hline Female breast & 4.8 & - & 9.5 & 0.0 & 1.6 & 5.8 & 6.7 & 5.7 & 5.5 & 4.9 & 4.0 & 3.1 \\
\hline Colon & 5.8 & 6.4 & 5.2 & 0.2 & 1.0 & 3.0 & 4.1 & 6.0 & 7.5 & 7.3 & 5.0 & 3.1 \\
\hline Lung & 6.5 & 9.5 & 3.5 & 0.0 & 0.9 & 5.0 & 11.5 & 15.7 & 12.6 & 5.8 & 1.8 & 0.4 \\
\hline Prostate & 5.1 & 10.2 & - & 0.1 & 0.0 & 0.2 & 0.6 & 2.2 & 5.7 & 7.6 & 5.6 & 2.2 \\
\hline Other cancers & 26.3 & 30.4 & 22.3 & 20.6 & 14.9 & 20.3 & 29.2 & 36.2 & 37.1 & 29.4 & 19.0 & 10.7 \\
\hline Psychiatric disorders & 9.7 & 9.7 & 9.8 & 4.8 & 21.7 & 27.1 & 22.6 & 15.2 & 10.0 & 8.0 & 6.5 & 4.4 \\
\hline Psychotic disorders & 1.8 & 1.9 & 1.8 & 0.1 & 6.7 & 7.3 & 5.1 & 3.2 & 2.2 & 1.4 & 0.8 & 0.5 \\
\hline Manic disorders & 0.8 & 0.65 & 1.0 & 0.0 & 1.5 & 2.5 & 1.7 & 1.4 & 1.0 & 0.8 & 0.4 & 0.2 \\
\hline Depression & 2.9 & 2.3 & 3.4 & 0.1 & 4.8 & 7.1 & 6.1 & 4.1 & 2.7 & 2.5 & 2.2 & 1.6 \\
\hline Addictive disorders & 2.0 & 3.0 & 0.9 & 0.0 & 8.2 & 12.2 & 10.1 & 5.1 & 1.9 & 0.6 & 0.2 & 0.1 \\
\hline Psychotropic treatments ${ }^{a}$ & 27.2 & 23.9 & 30.5 & 4.4 & 10.1 & 16.0 & 20.3 & 22.9 & 24.9 & 27.9 & 31.2 & 30.6 \\
\hline Neurological or degenerative diseases & 24.6 & 19.7 & 29.4 & 18.6 & 10.5 & 10.4 & 9.7 & 8.8 & 11.8 & 25.7 & 37.1 & 33.1 \\
\hline Dementias (Alzheimer) & 18.7 & 13.3 & 24.1 & 0.2 & 0.3 & 0.4 & 0.8 & 1.8 & 5.6 & 19.6 & 32.6 & 30.3 \\
\hline Parkinson's disease & 3.9 & 4.1 & 3.7 & 0.1 & 0.1 & 0.0 & 0.2 & 0.7 & 2.4 & 5.8 & 5.3 & 2.8 \\
\hline Multiple sclerosis & 0.2 & 0.2 & 0.3 & 0.0 & 0.3 & 0.6 & 0.6 & 0.6 & 0.4 & 0.2 & 0.1 & 0.0 \\
\hline Paraplegia & 0.4 & 0.5 & 0.3 & 1.2 & 1.3 & 1.1 & 0.7 & 0.6 & 0.5 & 0.3 & 0.2 & 0.1 \\
\hline Myopathy, myasthenia & 0.2 & 0.3 & 0.2 & 2.5 & 1.3 & 0.6 & 0.5 & 0.4 & 0.3 & 0.2 & 0.1 & 0.1 \\
\hline Epilepsy & 2.8 & 3.0 & 2.6 & 11.5 & 5.6 & 6.6 & 5.9 & 4.1 & 2.9 & 2.4 & 2.0 & 1.2 \\
\hline Chronic respiratory diseases & 20.5 & 24.2 & 16.8 & 19.0 & 7.0 & 10.4 & 16.0 & 22.6 & 25.1 & 24.0 & 18.3 & 12.3 \\
\hline Inflammatory or rare diseases or HIV or AIDS & 4.3 & 3.9 & 4.6 & 9.4 & 3.9 & 5.0 & 5.4 & 4.4 & 4.6 & 4.8 & 3.9 & 2.0 \\
\hline Treated renal failure & 1.4 & 1.8 & 1.1 & 0.1 & 0.6 & 1.1 & 1.3 & 1.5 & 2.4 & 2.0 & 0.9 & 0.2 \\
\hline
\end{tabular}


Table 1 Diseases managed of general scheme beneficiaries who died in 2013, according to sex and age (Continued)

\begin{tabular}{|c|c|c|c|c|c|c|c|c|c|c|c|c|}
\hline & \multirow[t]{2}{*}{ Total } & \multicolumn{2}{|l|}{ Sex } & \multicolumn{9}{|l|}{ Age } \\
\hline & & Men & Women & $<15$ & $15-34$ & $35-44$ & $45-54$ & $55-64$ & $65-74$ & $75-84$ & $85-94$ & $\geq 95$ \\
\hline N & 347,253 & 172,591 & 174,662 & 1066 & 4409 & 7030 & 18,860 & 39,656 & 50,638 & 89,933 & 114,652 & 21,009 \\
\hline$\%$ & 100.0 & 49.7 & 50.3 & 0.3 & 1.3 & 2.0 & 5.4 & 11.4 & 14.6 & 25.9 & 33.0 & 6.1 \\
\hline Diseases of the liver or of pancreas & 8.9 & 11.5 & 6.4 & 9.2 & 7.7 & 15.0 & 20.6 & 17.9 & 14.7 & 7.9 & 3.2 & 1.3 \\
\hline Other long-term diseases & 10.8 & 9.0 & 12.6 & 15.6 & 7.1 & 6.6 & 6.8 & 7.9 & 9.0 & 10.6 & 12.9 & 15.6 \\
\hline Maternity & 0.05 & - & 0.1 & - & 1.6 & 1.1 & 0.1 & - & - & - & - & - \\
\hline None of health states above & 4.4 & 4.9 & 3.9 & 34.4 & 38.2 & 19.2 & 10.0 & 5.1 & 2.7 & 2.1 & 2.8 & 6.7 \\
\hline
\end{tabular}

${ }^{a}$ with or without psychiatric disorders

between the ages of 55 and 74 years, men: 49\%; women: $36 \%$ ), dementia in $19 \%$ of cases (men: $13 \%$; women: $24 \%$ ) , and chronic respiratory disease in $20 \%$ of cases (men: 24\%: women: $18 \%)$.

\section{Hospitalizations and place death}

During the year preceding death, $83 \%$ of people were hospitalized at least once (short stay hospitals: 83\%, Rehab: 23\%, HaH: 7\%) (Table 1). These proportions were slightly higher for men except for hospitalizations in rehabilitation units (men: 21\%; women: 24\%). Analysis according to age revealed a high hospitalization rate before the age of 15 years (81\%), lower rates between the ages of 15 and 34 years (59\%), followed by rates that gradually increased with age until the 75 to 84 years age-group $(88 \%)$. Although the frequency of at least one Rehab admission to a rehabilitation unit increased regularly with age, the frequency of $\mathrm{HaH}$ decreased from the 6574 years age-group. Fig. I present a dynamic view of the proportion of people in each place of residence on a given day during the year before death. The proportion of people receiving $\mathrm{HPC}$ at least once during the year and admitted to a short stay hospital on a given day rapidly increased over the months preceding death: 9\% six months before death, $16 \%$ three months before death, $34 \%$ one month before death and $69 \%$ on the day of death. An increased admission rate was also observed for rehabilitation units (one month before death: 9\%, on the day of death: $13 \%)$ and $\mathrm{HaH}$ (6\% vs 9\%). Inversely, the proportion of people not hospitalized and not living in a $\mathrm{SNH}$ decreased markedly (one month before death: $44 \%$, 14 days before death: $29 \%$, on the day of death: $6 \%$ ). The proportion of people living in a $\mathrm{SNH}$ started to decrease three weeks before death $(6 \%)$ to reach $3 \%$ on the day of death. These variations differed or were less marked in the absence of HPC during the year before death, with a moderate increase for short stay hospital admissions (six months before death: 4\%, three months before death: $6 \%$, one month before death: $13 \%$, on the day of death: 44\%), stable Rehab admissions (4\%), and a moderate reduction for "other places" of residence (one month before death: $63 \%, 14$ days before death: $55 \%$, on the day of death: $35 \%$ ) and SNH (three weeks before death: $21 \%$, on the day of death: $17 \%)$.

Overall, death occurred in hospital for $58 \%$ of deceased people (51\% in short stay hospitals, $7 \%$ in Rehab), in $\mathrm{HaH}$ for 3\%, in $\mathrm{SNH}$ for $13 \%$ and in "other places" for $26 \%$ (public place, home, retirement home, etc.) (Table 2). A higher proportion of women died in $\mathrm{SNH}$ (19\% vs $7 \%$ for men), but with a different mean age. A higher proportion of men died in short stay hospitals (55\% vs $47 \%$ for women) and in "other places" (29\% vs $24 \%)$. The proportion of deaths in SNH increased markedly after the age of 85 years, while the proportion of deaths in "other places" reached a peak of $60 \%$ between the ages of 15 and 34 years and the proportion of deaths in short stay hospitals reached a peak of $60 \%$ between the ages of 55 and 74 years. The proportion of deaths in rehabilitation units increased slightly with age and the proportion of deaths in $\mathrm{HaH}$ decreased after the age of 74 years. Sixty-four per cent of people managed for cancer died in a short stay hospital, 7\% died in a $\mathrm{SNH}$ and $16 \%$ died outside of a hospital, $\mathrm{HaH}$ or a SNH. The proportions of deaths in SNH (16\%) and outside of a hospital, $\mathrm{HaH}$ or a $\mathrm{SNH}(23 \%)$ were higher among people with cardiovascular diseases (other than cancer) than for the overall population. These proportions were even higher for people with neurological or degenerative diseases: death in a NSH: $35 \%$ and death outside of a hospital or a NSH: $23 \%$.

\section{Use of hospital palliative care}

Twenty-nine per cent of all deceased people received hospital palliative care at the date of death or during the year preceding death (Table 3 ). This proportion varied little according to sex (men: 30\%; women: 28\%), but more markedly according to age, with $30 \%$ for people under the age of 15 years and a peak around 39\% between the ages of 55 and 74 years; and also according to CMU-C status (presence: 28\%; absence: 34\%). People managed for cancer received HPC in 52\% of cases (lung cancer $62 \%$; prostate cancer: $41 \%$ ), while people with other diseases, excluding cancer, received HPC in $24 \%$ of cases for acute stroke, $17 \%$ of cases for heart failure, $23 \%$ 
Table 2 Place of death in 2013 according to the general scheme beneficiaries characteristics and diseases managed

\begin{tabular}{|c|c|c|c|c|c|c|}
\hline Place of death & & Short stay hospital & Rehab & $\begin{array}{l}\text { Hospital } \\
\text { at home }\end{array}$ & $\begin{array}{l}\text { Skilled nursing } \\
\text { home }\end{array}$ & Other \\
\hline & $\mathrm{n}^{\mathrm{a}}$ & $\%$ & $\%$ & $\%$ & $\%$ & $\%$ \\
\hline Total & 347.3 & 51.0 & 6.5 & 2.8 & 13.3 & 26.4 \\
\hline Men & 172.6 & 54.8 & 6.1 & 2.9 & 7.3 & 28.9 \\
\hline Women & 174.7 & 47.1 & 6.8 & 2.8 & 19.3 & 23.9 \\
\hline \multicolumn{7}{|l|}{ Age (years) } \\
\hline$<15$ & 1.1 & 59.7 & 1.4 & 4.2 & & 34.7 \\
\hline $15-34$ & 44 & 37.6 & 0.9 & 1.7 & & 59.7 \\
\hline $35-44$ & 70 & 45.8 & 1.6 & 2.3 & 0.1 & 50.2 \\
\hline $45-54$ & 189 & 55.4 & 3.0 & 2.8 & 0.2 & 38.6 \\
\hline $55-64$ & 397 & 60.7 & 4.5 & 3.5 & 1.2 & 30.2 \\
\hline $65-74$ & 506 & 62.0 & 5.6 & 3.6 & 3.2 & 25.7 \\
\hline $75-84$ & 89.9 & 55.3 & 7.7 & 3.1 & 9.8 & 24.1 \\
\hline $85-94$ & 1147 & 43.6 & 8.0 & 2.3 & 23.5 & 22.6 \\
\hline$\geq 95$ & 210 & 27.5 & 5.2 & 1.8 & 40.2 & 25.3 \\
\hline Cancers & 146.2 & 63.6 & 8.3 & 4.7 & 7.0 & 16.4 \\
\hline Female breast & 16.5 & 58.9 & 8.2 & 4.5 & 11.1 & 17.3 \\
\hline Colon & 20.1 & 62.0 & 8.9 & 5.0 & 8.0 & 16.1 \\
\hline Lung & 22.5 & 71.1 & 8.2 & 5.0 & 2.3 & 13.4 \\
\hline Prostate & 17.6 & 56.5 & 8.3 & 4.4 & 8.9 & 21.9 \\
\hline Other cancers & 91.4 & 64.9 & 8.4 & 4.9 & 6.5 & 15.4 \\
\hline \multicolumn{7}{|l|}{ Other diseases in the absence of cancer } \\
\hline Cardiovascular/neurovascular diseases & 121.4 & 53.2 & 6.5 & 1.6 & 16.1 & 22.6 \\
\hline Coronary heart disease & 45.0 & 56.1 & 6.3 & 1.4 & 13.0 & 23.2 \\
\hline Acute stroke & 12.9 & 75.5 & 7.9 & 1.3 & 9.1 & 6.1 \\
\hline Stroke sequelae & 21.7 & 46.2 & 6.3 & 2.1 & 21.9 & 23.4 \\
\hline Heart failure & 57.3 & 59.3 & 7.1 & 1.6 & 13.9 & 18.1 \\
\hline Diabetes & 43.3 & 48.2 & 5.7 & 1.7 & 12.5 & 31.9 \\
\hline Psychiatric disorders & 23.9 & 34.8 & 4.0 & 0.8 & 16.2 & 44.1 \\
\hline Neurological or degenerative diseases & 63.4 & 37.4 & 6.0 & 2.3 & 31.7 & 22.6 \\
\hline Dementias (including Alzheimer) & 50.2 & 35.4 & 6.4 & 2.2 & 35.8 & 20.2 \\
\hline Parkinson's disease & 10.0 & 38.9 & 6.1 & 2.6 & 28.0 & 24.4 \\
\hline Multiple sclerosis & 0.6 & 48.5 & 1.8 & 5.0 & 12.0 & 32.7 \\
\hline Paraplegia & 0.8 & 51.0 & 5.1 & 3.8 & 10.1 & 30.0 \\
\hline Myopathy or myasthenia & 0.6 & 58.4 & 3.1 & 3.1 & 5.9 & 29.4 \\
\hline Epilepsy & 6.1 & 44.5 & 4.5 & 2.3 & 18.0 & 30.8 \\
\hline Chronic respiratory diseases & 39.0 & 56.2 & 5.7 & 1.6 & 10.4 & 26.1 \\
\hline Inflammatory or rare diseases, HIV or AIDS & 9.0 & 55.2 & 6.1 & 1.7 & 11.8 & 25.2 \\
\hline Treated renal failure & 3.3 & 72.2 & 3.1 & 1.6 & 5.1 & 18.0 \\
\hline Diseases of the liver or pancreas & 14.6 & 70.5 & 4.5 & 1.0 & 4.2 & 19.9 \\
\hline Other long-term diseases & 24.2 & 42.9 & 5.6 & 2.0 & 19.8 & 29.7 \\
\hline
\end{tabular}

${ }^{\mathrm{a} T h o u s a n d}$ 
Table 3 Hospital palliative care use at the time of death, during the last year (total), or before death for people died in a skilled nursing home or in another place according to sex, age and disease managed

\begin{tabular}{|c|c|c|c|c|c|c|c|c|c|c|c|c|c|}
\hline \multirow[t]{2}{*}{ Place of deaths } & \multicolumn{3}{|c|}{ All places } & \multicolumn{2}{|c|}{$\begin{array}{l}\text { Short stay } \\
\text { hospital }\end{array}$} & \multicolumn{2}{|l|}{ Rehab } & \multicolumn{2}{|c|}{$\begin{array}{l}\text { Hospital } \\
\text { at home }\end{array}$} & \multicolumn{2}{|c|}{$\begin{array}{l}\text { Skilled nursing } \\
\text { home\# }\end{array}$} & \multicolumn{2}{|c|}{ Other $^{b}$} \\
\hline & $\overline{\mathrm{N}^{\mathrm{a}}}$ & Death $^{\circ}$ & Total & $\overline{N^{a}}$ & $\overline{\text { Total }}$ & $\overline{\mathrm{N}^{\mathrm{a}}}$ & Total & $\mathrm{N}^{\mathrm{a}}$ & Total & $\mathrm{N}^{a}$ & Before death & $\overline{\mathrm{N}^{\mathrm{a}}}$ & Before death \\
\hline & & $\%$ & $\%$ & & $\%$ & & $\%$ & & & & $\%$ & & $\%$ \\
\hline Total & 347.3 & 15.7 & 29.2 & 176.9 & 39.3 & 22.51 & 60.0 & 9.82 & 88.9 & 46.3 & 7.6 & 91.7 & 6.7 \\
\hline Men & 172.6 & 16.6 & 30.9 & 94.6 & 40.1 & 10.55 & 60.9 & 4.97 & 90.2 & 12.6 & 9.6 & 49.8 & 6.5 \\
\hline Women & 174.7 & 14.9 & 27.6 & 82.3 & 38.5 & 11.96 & 59.1 & 4.84 & 87.5 & 33.8 & 6.8 & 41.8 & 7.0 \\
\hline \multicolumn{14}{|l|}{ Age (years) } \\
\hline$<15$ & 1.1 & 11.5 & 30.3 & 0.6 & 38.2 & 0.02 & 93.3 & 0.05 & 95.6 & & - & 0.4 & 6.2 \\
\hline $15-34$ & 4.4 & 6.6 & 15.8 & 1.7 & 33.3 & 0.04 & 58.5 & 0.08 & 100 & & - & 2.6 & 1.6 \\
\hline $35-44$ & 7.0 & 10.7 & 25.4 & 3.2 & 45.4 & 0.11 & 68.4 & 0.16 & 95 & 0.0 & - & 3.5 & 2.6 \\
\hline $45-54$ & 18.9 & 15.9 & 34.5 & 10.4 & 49.7 & 0.56 & 80.0 & 0.54 & 96.6 & 0.0 & - & 7.3 & 4.8 \\
\hline $55-64$ & 39.7 & 19.4 & 39.9 & 24.1 & 50.5 & 1.77 & 79.4 & 1.38 & 95.3 & 0.5 & 16.0 & 12.0 & 7.3 \\
\hline $65-74$ & 50.6 & 19.8 & 38.8 & 31.4 & 46.5 & 2.81 & 71.1 & 1.81 & 92.8 & 1.6 & 14.0 & 13.0 & 8.5 \\
\hline $75-84$ & 89.9 & 17.6 & 31.7 & 49.8 & 38.2 & 6.92 & 63.3 & 2.78 & 89.1 & 8.8 & 10.0 & 21.6 & 8.2 \\
\hline $85-94$ & 114.7 & 13.3 & 22.2 & 50.0 & 29.9 & 9.20 & 50.9 & 2.66 & 81.7 & 26.9 & 7.3 & 25.9 & 6.6 \\
\hline$\geq 95$ & 21.0 & 8.4 & 13.2 & 5.8 & 25.6 & 1.09 & 42.9 & 0.37 & 77.8 & 8.4 & 3.8 & 5.3 & 3.9 \\
\hline Cancers & 146.2 & 25.9 & 51.9 & 93.0 & 57.8 & 12.19 & 76.4 & 6.86 & 94.5 & 10.3 & 18.0 & 23.9 & 19.0 \\
\hline Female breast & 16.5 & 24.5 & 50.1 & 9.7 & 59.6 & 1.35 & 75.7 & 0.74 & 93.9 & 1.8 & 15.0 & 2.9 & 17.0 \\
\hline Colon & 20.1 & 25.9 & 52.7 & 12.5 & 57.9 & 1.80 & 76.8 & 1.01 & 94.6 & 1.6 & 20.0 & 3.2 & 22.0 \\
\hline Lung & 22.5 & 30.5 & 62.5 & 16.0 & 65.5 & 1.84 & 84.3 & 1.12 & 97 & 0.5 & 35.0 & 3.0 & 25.0 \\
\hline Prostate & 17.6 & 20.8 & 40.9 & 9.9 & 48.0 & 1.46 & 67.2 & 0.78 & 92.2 & 1.6 & 14.0 & 3.8 & 13.0 \\
\hline Other cancers & 91.4 & 26.4 & 53.3 & 59.3 & 58.5 & 7.68 & 77.1 & 4.47 & 94.7 & 5.9 & 19.0 & 14.0 & 20.0 \\
\hline \multicolumn{14}{|l|}{ Other diseases in the absence of cancer } \\
\hline Cardiovascular/neurovascular diseases & 121.4 & 10.7 & 15.9 & 64.6 & 19.0 & 7.88 & 40.3 & 1.96 & 74.9 & 19.5 & 6.4 & 27.5 & 4.0 \\
\hline Coronary heart disease & 45.0 & 10.0 & 14.9 & 25.3 & 17.4 & 2.82 & 38.3 & 0.63 & 76.5 & 5.9 & 6.3 & 10.4 & 3.6 \\
\hline Acute stroke & 12.9 & 18.2 & 24.3 & 9.7 & 22.6 & 1.02 & 51.6 & 0.17 & 77.9 & 1.2 & 16.0 & 0.8 & 11.0 \\
\hline Stroke sequelae & 21.7 & 11.5 & 18.0 & 10.0 & 24.2 & 1.37 & 41.5 & 0.46 & 76.6 & 4.8 & 6.0 & 5.1 & 5.3 \\
\hline Heart failure & 57.3 & 11.5 & 17.3 & 34.0 & 19.1 & 4.07 & 39.3 & 0.90 & 78 & 8.0 & 7.0 & 10.4 & 5.2 \\
\hline Diabetes & 43.3 & 9.2 & 14.1 & 20.9 & 18.3 & 2.45 & 40.2 & 0.76 & 75.8 & 5.4 & 6.1 & 13.8 & 2.9 \\
\hline Psychiatric disorders & 23.9 & 6.6 & 10.5 & 8.3 & 19.1 & 0.96 & 36.9 & 0.20 & 76.2 & 3.9 & 5.1 & 10.6 & 1.9 \\
\hline Neurological or degenerative diseases & 63.4 & 10.9 & 17.4 & 23.7 & 27.1 & 3.83 & 44.9 & 1.44 & 75.4 & 20.1 & 5.3 & 14.3 & 5.0 \\
\hline Dementias (including Alzheimer) & 50.2 & 11.0 & 17.2 & 0.0 & 27.4 & 3.21 & 44.7 & 1.10 & 75 & 0.0 & 5.4 & 0.0 & 5.4 \\
\hline Parkinson's disease & 10.0 & 11.6 & 17.7 & 17.8 & 27.4 & 0.61 & 46.8 & 0.26 & 71.7 & 18.0 & 4.6 & 10.1 & 4.0 \\
\hline Multiple sclerosis & 0.6 & 10.2 & 23.2 & 3.9 & 28.9 & 0.01 & 63.6 & 0.03 & 80 & 2.8 & 8.3 & 2.4 & 9.2 \\
\hline Paraplegia & 0.8 & 10.4 & 20.6 & 0.3 & 26.2 & 0.04 & 44.2 & 0.03 & 62.5 & 0.1 & 5.9 & 0.2 & 6.7 \\
\hline Myopathy or myasthenia & 0.6 & 14.2 & 21.2 & 0.4 & 27.4 & 0.02 & 55.6 & 0.02 & 72.2 & 0.1 & 2.9 & 0.3 & 3.6 \\
\hline Epilepsy & 6.1 & 11.3 & 18.4 & 0.3 & 26.3 & 0.27 & 52.8 & 0.14 & 75.5 & 0.0 & 7.2 & 0.2 & 4.4 \\
\hline Chronic respiratory diseases & 39.0 & 10.4 & 16.5 & 2.7 & 19.9 & 2.24 & 37.7 & 0.61 & 77.4 & 1.1 & 7.1 & 1.9 & 4.4 \\
\hline Inflammatory or rare diseases, HIV or AIDS & 9.0 & 11.0 & 17.3 & 21.9 & 20.9 & 0.55 & 44.2 & 0.15 & 81.3 & 4.1 & 6.3 & 10.2 & 3.8 \\
\hline Treated renal failure & 3.3 & 12.4 & 20.4 & 4.9 & 22.2 & 0.10 & 46.0 & 0.05 & 80.8 & 1.1 & 14.0 & 2.3 & 5.3 \\
\hline Diseases of the liver or pancreas & 14.6 & 10.7 & 16.7 & 2.3 & 17.5 & 0.65 & 47.2 & 0.15 & 86.4 & 0.2 & 11.0 & 0.6 & 4.7 \\
\hline Other long-term diseases & 24.2 & 9.7 & 15.1 & 10.3 & 21.5 & 1.36 & 40.0 & 0.48 & 74.5 & 0.6 & 5.3 & 2.9 & 3.7 \\
\hline
\end{tabular}


of cases for multiple sclerosis, $18 \%$ of cases for Parkinson's disease, $17 \%$ of cases for dementia, $16 \%$ of cases for chronic respiratory disease and $20 \%$ of cases for treated renal failure. In more than one-half of cases, HPC was only provided during the stay associated with death $(13 \%$ of people received HPC before the stay resulting in death, while $16 \%$ only received HPC during the stay resulting in death, for a total of $29 \%$ of people receiving HPC). Access to HPC during the year before death decreased with age and was less frequent in the absence of cancer. Among the people who died in a $\mathrm{NSH}$, not equipped with a palliative care unit identified in the Snds database, $8 \%$ had previously received HPC, especially between the ages of 65 and 84 years and in the presence of a cancer (17\%). HPC before death was also observed in the "Other places" category (7\%), with higher rates for older people, in the presence of a cancer (19\%) and, to a lesser extent, in the presence of multiple sclerosis $(9 \%)$ or acute stroke (11\%). Thirty-five per cent of people who died during other types of hospitalization than short stay hospitals (in rehabilitation units or $\mathrm{HaH}$ ) had received HPC before death and 69\% had received HPC at the date of death.

\section{Discussion}

In a large population of deceased people, $60 \%$ died in a hospital setting and one-half died in a short stay hospital. The proportion of people hospitalized in a short stay hospital increased rapidly over the three months prior to death. The main chronic diseases managed one year before death were cardiovascular/neurovascular diseases $(56 \%)$, cancers (42\%), and neurological and degenerative diseases (25\%). During the year before death, $84 \%$ of people were hospitalized at least once, and $29 \%$ received HPC. HPC was more frequently used by cancer patients, and, in the absence of cancer, by patients with stroke: $24 \%$, heart failure: $17 \%$, dementia: $17 \%$, multiple sclerosis: $23 \%$.

\section{Comparisons of places of death and diagnosis with French mortality statistics}

This study was based on very comprehensive administrative and hospital reimbursement data and a large national study population [22]. The results can be compared with the national population and mortality statistics. Characteristics of deceased general scheme beneficiaries are relatively similar to those of all people who died in France in 2013, but with a smaller proportion of older people compared to the overall population (mean age: men: 73 years vs 79 years, women: 81 vs 85 years) [25]. General scheme beneficiaries are globally younger than beneficiaries of other schemes, which explain why this study included only $61 \%$ of all deaths in France, for $77 \%$ of the population.
In all deaths in 2013 in France, 57\% occurred in hospital, $12 \%$ in retirement homes, $25 \%$ at home and $6 \%$ in a public place or in "Other places" [25]. These figures are similar to those reported in this study: $58 \%$ of people died in hospital, $13 \%$ died in a SNH and $29 \%$ died in "other places" (including 3\% in $\mathrm{HaH}$ ). However, SNH do not include all retirement homes and the proportion of $\mathrm{SNH}$ is unknown. This study was unable to directly estimate the proportion of deaths at home, but $29 \%$ of deaths occurred outside of hospitals and $\mathrm{SNH}$ and therefore theoretically at home (including $\mathrm{HaH}$ ) or in a public place. As reported in other countries, a very great majority of French people (85\%), free of any serious diseases, prefer to die at home [26]. However, in this study, only $42 \%$ of people died at home if SNH and "Other places" were considered to be home. This proportion decreased to $36 \%$ after subtracting the $6 \%$ of nationwide deaths in a public place [25].

End of life can be associated with a context of multiple diseases that cannot be reflected by a single leading cause of death. The distribution of diagnoses identified by subject in our study does not correspond to all causes of death in 2013: tumours (42\% in this study for $29 \%$ as the leading cause of death), cardiovascular disease (56\% for $25 \%)$, respiratory tract disease (20\% for $7 \%$ ), and dementia (19\% for $4 \%$ ) [25]. However, some causes of death were not included in the diagnoses because they could not be identified using the Snds database algorithms.

\section{Hospital palliative care use}

Twenty-nine per cent of all deceased people received HPC at the date of death or during the year preceding death (16\% at the date of death only, and $13 \%$ at least before death). These rates were $39 \%$ for deaths in short stay hospitals and $44 \%$ for all deaths in health care institutions. These rates correspond to a first estimate of HPC use in a large population in France and few data on this subject using hospital diagnosis are available in the international literature $(15-17,19)$. The results of published studies correspond more to HPC needs, than HPC use, estimated by algorithms using causes of death likely to benefit from palliative care. HPC needs vary according to the causes of death eliminated or included in the algorithm and their specific distributions in different populations [8]. Hospital diagnoses matched with causes of death were also used in an Australian study [19]. The number of people with palliative care needs in France in 2008 was estimated to be $41 \%$ of all deaths according to the method of Rosenwax et al. and 69\% according to the method of Murtagh et al., which includes more causes of death [8, 27], such as chronic cardiovascular / neurovascular diseases other than heart failure, non-Alzheimer's dementia and respiratory diseases other than chronic obstructive pulmonary disease. Thus, considering available data, estimation of palliative 
care need by health policymakers could be over or underestimated when national institution. Hospital diagnosis and multiple cause-of-deaths must be considered because cancer diagnosis may not be notified as the main or primary cause of death. While it is recommended to initiate palliative care earlier before death, the rate of palliative care use before death is relatively low in this study, except in rehabilitation units and $\mathrm{HaH}$, which can constitute a short-stay alternative providing more specialized services in this field.

The frequency of palliative care before and at the date of death varies according to the type of disease, as well as their age and sex distributions, such as the classical high proportion of external causes in young boys. The type of palliative care can also vary according to age and type of disease. Analysis of HPC use by disease therefore appears to be more relevant than by causes of death, although other characteristics can also influence management, such as gender, age, and comorbidities.

\section{Strength and limits}

Use of palliative care in France is probably underestimated because this study does not take into palliative care managed by the general practitioner at home or palliative care provided in NSH, as no specific markers, such as drug reimbursements, are available due to the lack of specificity. However, $5 \%$ of deceased people received HPC before death in a NSH or in "other places", suggesting return or continued management of the patient at home or in a NSH, but the intensity of this care cannot be assessed.

The diseases managed can be identified by multisource algorithms such as those used in this study. These algorithms have been submitted to sensitivity analyses and expert reviews [24]. However, they depend on the use, offer and access to care. The data analyzed in this study were derived from administrative databases with their classical limitations concerning their primary objective, i. e. data collection and coding.

As part of the process of reflection on the end of life, the Snds can be used to describe end-of-life pathways and places of death and will soon be linked to causes of death. In the context of the new national palliative care plan in France, the Snds could be used to monitor several indicators focusing on HPC use, place of death but also to conduct more specific analyses in order to improve or evaluate specific subgroups (people with cancers, younger or older people, treatments and drugs used before death according to the disease).

\section{Conclusion}

This study suggests a relatively high level of HPC use in France, especially for certain diseases and in $\mathrm{HaH}$ and rehab hospitals. Few people were hospitalized with HPC care recorded in the database before the last hospitalization before death or before return home. In the context of a reflection on the end of life, these results must be refined in order to elucidate various specific aspects (diseases, disparity of use, etc.) based on Snds data, but also with the help of healthcare professionals and patients, in order to guide end-of-life health policies and evaluate heath policies and improve monitoring, such as the national plan, and assessment of HPC use.

\section{Additional file}

Additional file 1: Algorithms designed to identify beneficiaries reimbursed for chronic diseases and common, serious or expensive diseases and treatments. (DOC $102 \mathrm{~kb}$ )

\section{Abbreviations}

Cnam: Caisse Nationale d'Assurance Maladie general health scheme fund; $\mathrm{HaH}$ : Hospital at home; HPC: Hospital palliative care; ICD-10: International classification of diseases, 10th edition; LTD: Long-term diseases; PMSI: Programme de médicalisation des systèmes d'information (PMSI) [Medical Information System Programme]; Rehab: Rehabilitation unit; SNH: skilled nursing homes; Snds Système National des données de santé [National Health data Information System]

\section{Availability of data and materials}

Datasets are localised at Cnam and access is authorized by the CNIL (French data protection authority). All data were encrypted using a unique identifier and all records used were anonymized.

\section{Authors' contributions}

$C P, A F C, P T$ and RA designed the study. $L R B, C R$ drafted the article or revised it critically for important intellectual content. CP carried out data analysis. All authors made a substantial contribution to analysis or interpretation of data and approved the version to be published. All authors read and approved the final manuscript.

Ethics approval and consent to participate

This study was based on an administrative database (Snds) used for reimbursement. Analyses of Snds data by Cnam were performed with the permission of the CNIL (French data protection authority) and by decree.

\section{Competing interests}

The authors declare that they have no competing interest.

\section{Publisher's Note}

Springer Nature remains neutral with regard to jurisdictional claims in published maps and institutional affiliations.

\section{Author details}

${ }^{1}$ National sickness insurance fund, 26-50, avenue du Professeur André Lemierre, 75986 Paris cedex 20, France. ${ }^{2}$ National Palliative care and end of life center, 75020 Paris, France. ${ }^{3}$ Health Education and Practices Laboratory, Paris XIII University EA 3412, 93017 Bobigny cedex, France. ${ }^{4}$ Pain and palliative Care Department, Teaching Hospital, 25030, Besançon, France.

Received: 7 March 2018 Accepted: 30 April 2018

Published online: 16 May 2018

\section{References}

1. Parikh RB, Kirch RA, Smith TJ, Temel JS. Early specialty palliative care-translating data in oncology into practice. N Engl J Med. 2013;369(24):2347-51.

2. Blanpain $\mathrm{N}$, I'horizon COP d p à. Un tiers de la population âgé de plus de 60 ans. Institut national de la statistique et des études économiques (Insee). Insee Première. 2060;2010:1320. www.insee.fr 
3. Gilles Pison, Laurent Toulemon. Le nombre de décès va augmenter en France dans les prochaines années. Institut national des études démographiques (INED). Population et Sociétés 2016;531. https://www.ined. $\mathrm{fr} /$

4. Murray SA, Kendall M, Boyd K, Sheikh A. Illness trajectories and palliative care. BMJ. 2005:330(7498):1007-11.

5. Plan triennal 2015-2018 pour le développement des soins palliatifs et l'accompagnement en fin de vie. Ministère des Affaires sociales. In: de la Santé et des Droits des femmes; 2014. www.social-sante.gouv.fr.

6. Aubry R. Comité national de suivi du développement des soins palliatifs et de l'accompagnement. Bilan du Programme national de développement des soins palliatifs 2008-2012. Ministère des Affaires sociales. In: de la Santé et des Droits des femmes; 2013. www.social-sante.gouv.fr.

7. Pivodic L, Pardon K, Morin L, et al. Place of death in the population dying from diseases indicative of palliative care need: a cross-national population-level study in 14 countries. J Epidemiol Community Health. 2016;70(1):17-24.

8. Murtagh FE, Bausewein C, Verne J, Groeneveld El, Kaloki YE, Higginson IJ. How many people need palliative care? A study developing and comparing methods for population-based estimates. Palliat Med. 2014;28(1):49-58.

9. Morin L, Aubry R, Frova L, et al. Estimating the need for palliative care at the population level: a cross-national study in 12 countries. Palliat Med. 2016; 31(6):526-36.

10. Sarmento VP, Higginson IJ, Ferreira PL, Gomes B. Past trends and projections of hospital deaths to inform the integration of palliative care in one of the most ageing countries in the world. Palliat Med. 2016;30(4):63-73.

11. Scholten N, Günther AL, Pfaff H, Karbach U. The size of the population potentially in need of palliative care in Germany-an estimation based on death registration data. BMC Palliat Care. 2016;15:29.

12. Kane PM, Daveson BA, Ryan K, McQuillan R, Higginson IJ, Murtagh FE; BuildCARE. The need for palliative care in Ireland: a population-based estimate of palliative care using routine mortality data, inclusive of nonmalignant conditions. J Pain Symptom Manage 2015;49(4):726-733.e1.

13. Gómez-Batiste X, Martínez-Muñoz M, Blay C, Amblàs J, Vila L, Costa X, Espaulella J, Espinosa J, Constante C, Mitchell GK. Prevalence and characteristics of patients with advanced chronic conditions in need of palliative care in the general population: a cross-sectional study. Palliat Med. 2014;28(4):302-11.

14. Brameld K, Spilsbury K, Rosenwax L, Murray K, Semmens J. Issues using linkage of hospital records and death certificate data to determine the size of a potential palliative care population. Palliat Med. 2016;31(6):537-43.

15. Reich O, Signorell A, Busato A. Place of death and health care utilization for people in the last 6 months of life in Switzerland: a retrospective analysis using administrative data. BMC Health Serv Res. 2013;13:116.

16. Tanuseputro P, Budhwani S, Bai YQ, Wodchis WP. Palliative care delivery across health sectors: a population-level observational study. Palliat Med. 2017;31(3):247-57.

17. Teno JM, Gozalo PL, Bynum JP, et al. Change in end-of-life care for Medicare beneficiaries: site of death, place of care, and health care transitions in 2000, 2005, and 2009. JAMA. 2013:309(25):470-7.

18. Bekelman JE, Halpern SD, Blankart CR, et al. Comparison of site of death, health care utilization, and hospital expenditures for patients dying with Cancer in 7 developed countries. JAMA. 2016;315(3):272-83.

19. Goldsbury DE, O'Connell DL, Girgis A, et al. Acute hospital-based services used by adults during the last year of life in new South Wales, Australia: a population-based retrospective cohort study. BMC Health Serv Res. 2015;15: 537.

20. Atramont A, Rigault A, Chevalier S, Leblanc G, Fagot-Campagna A, Characteristics TP. Diseases and mortality of people admitted to nursing homes for dependent seniors during the first quarter of 2013 in France. Rev Epidemiol Sante Publique. 2017;65(3):221-30.

21. Scotté $F$, Hervé $C$, Leroy $P$, et al. Supportive Care Organization in France: a national in-depth survey among patients and oncologists. Support Care Cancer. 2017;25(7):2111-8.

22. Tuppin P, Rudant J, Constantinou P, Gastaldi-Ménager C, Rachas A, de Roquefeuil $L$, et al. Value of a national administrative database to guide public decisions: from the Système national d'Information Interrégimes de I'Assurance Maladie (SNIIRAM) to the Système national des Données de Santé (SNDS) in France. Rev Epidemiol Sante Publique. 2017;65(Suppl 4): S149-67.
23. Améliorer la qualité du système de santé et maîtriser les dépenses. Propositions de l'Assurance Maladie pour 2017. CNAMTS. 2016:224. www. ameli.fr.

24. Quantin C. Etude des algorithmes de définition des pathologies dans le Sniiram. CNAMTS;2015. www.ameli.fr

25. Centre d'épidémiologie sur les causes médicales de décès (CépiDc). www. cepidc.inserm.fr

26. Institut français d'opinion publique (IFOP) et ADREA mutuelle. Les attentes et les besoins des Français vis-à-vis de la fin de vie. 2016. www.adrea.fr/ assets/documents/DOCS-FONDATION/Diapo-rsum-IFOP.pdf.

27. Rosenwax LK, McNamara B, Blackmore AM, Holman CD. Estimating the size of a potential palliative care population. Palliat Med. 2005;19(7):556-62.

\section{Ready to submit your research? Choose BMC and benefit from:}

- fast, convenient online submission

- thorough peer review by experienced researchers in your field

- rapid publication on acceptance

- support for research data, including large and complex data types

- gold Open Access which fosters wider collaboration and increased citations

- maximum visibility for your research: over $100 \mathrm{M}$ website views per year

At BMC, research is always in progress.

Learn more biomedcentral.com/submissions 